\title{
Relação com o Saber na Escola em Tempo Integral
}

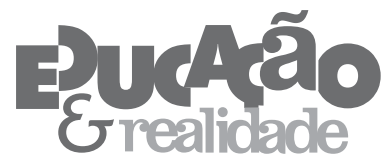

\author{
Maria Celeste Reis Fernandes Souza' \\ Bernard Charlot"
}

'Universidade Vale do Rio Doce (Univale), Governador Valadares/MG - Brasil

"Universidade Federal de Sergipe (UFS), Aracaju/SE - Brasil

RESUMO - Relação com o Saber na Escola em Tempo Integral. O artigo apresenta resultados de um estudo cujo objetivo é compreender as relações que estudantes dos anos finais do Ensino Fundamental estabelecem com o saber e a escola em Tempo Integral. Os marcos teórico e metodológico são os estudos de Bernard Charlot sobre a relação com o saber. A análise evidencia o binômio proteção/educação, e a relação ampliação do tempo e aprendizagem com suas tensões e contradições. As conclusões apontam que o tempo integral não pode ser uma simples ampliação da escola atual, mas deve ser um espaço-tempo em que aprender tenha sentido, ofereça novas oportunidades culturais e não inviabilize projetos institucionais ou individuais que têm um real valor de formação.

Palavras-chave: Educação Integral. Escola em Tempo Integral. Relação com o Saber.

ABSTRACT - Relation with Knowledge in the Full-Time School. This article presents partial results of a research that seeks to understand the relationships that students of final years of elementary school establish with knowledge and the Full-Time School. The theoretical and methodological frameworks are the studies of Bernard Charlot on the relation to knowledge. The analysis highlights the binomial protection/education, and the relationship expansion of time and learning with its tensions and contradictions. The conclusions indicate that the full-time can not be a simple extension of the current school, but should be a space-time where learning makes sense, offer new cultural opportunities and not hinder institutional or individual projects that have real value of formation.

Keywords: Integral Education. Full-Time School. Relations to Knowledge.

Educação \& Realidade, Porto Alegre, v. 41, n. 4, p. 1071-1093, out./dez. 2016.1071 http://dx.doi.org/10.1590/2175-623659843 
Relação com o Saber na Escola em Tempo Integral

\section{Apresentação}

A escola brasileira contemporânea possui muitos desafios a enfrentar: melhorar a qualidade da educação, universalizar o Ensino Médio, cuja taxa de escolarização fica atrás da de muitos dos países que competem no mundo globalizado, apropriar-se das tecnologias mais recentes de informação, construir uma escola em tempo integral. Para tanto, o Plano Nacional de Educação (PNE) para o decênio 2014-2024 (Brasil, 2014a) definiu um conjunto de metas estruturantes que visa “[...] a garantia do direito à educação básica com qualidade, que dizem respeito ao acesso, à universalização da alfabetização e à ampliação da escolaridade e das oportunidades educacionais" (Brasil, 2014b, p. 9).

Este texto tem como objeto de reflexão a temática do tempo integral, e apresenta resultados de uma pesquisa cujo objetivo foi compreender as relações que estudantes do $9^{\circ}$ ano do Ensino Fundamental (EF) estabelecem com saber e a Escola em Tempo Integral (ETI).

A pesquisa tem como cenário uma experiência de universalização de oferta do tempo integral, na rede de educação do município de Governador Valadares (MG), que ampliou, a partir de 2010, a jornada escolar de $4 \mathrm{~h}$ e 30 minutos para 8 horas de atividades diárias em todas as unidades escolares do $\mathrm{EF}^{1}$ da cidade e do campo.

A proposta da ETI é a formação integral e, por isso, na composição da jornada escolar, crianças e adolescentes participam das atividades escolares em um turno único - $7 \mathrm{~h}$ às $15 \mathrm{~h}$ - nesse mesmo turno, frequentam aulas disciplinares, ministradas em módulos de 50 minutos, e também oficinas (organizadas em módulos de 50 minutos) incorporadas ao currículo por meio do Programa Mais Educação - $\mathrm{PME}^{2}$. As atividades do PME (05 atividades por escola na época da realização do estudo) eram selecionadas no repertório das práticas disponibilizadas pelo Programa (judô, dança, jornal escolar etc.) e variavam de um ano para outro, conforme orientações do PME (Brasil 2014c).

O foco do estudo são estudantes que frequentam o $9^{\circ}$ ano com idade compreendida entre 14 e 17 anos. O ponto de partida da pesquisa foi o fato de que o número de alunos nos últimos anos do EF tem decrescido, desde a implantação da ETI, na grande maioria das escolas da rede municipal de educação. A análise dos dados quantitativos das

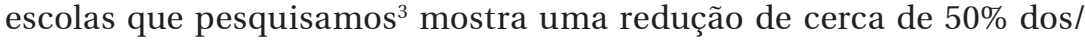
das estudantes na transição do $8^{\circ}$ para o $9^{\circ}$ ano. Estudantes ora migram para escolas estaduais que oferecem horário parcial, ora migram para a Educação de Jovens e Adultos no noturno ao completarem 15 anos, ou, simplesmente, saem da escola, como informam os sujeitos participantes deste estudo sobre o destino de alguns colegas.

O referencial teórico e metodológico se apoia na relação com o saber, como propõe Bernard Charlot, buscando, como indica o autor, praticar uma leitura em positivo dessa realidade (Charlot, 2009).

1072 Educação \& Realidade, Porto Alegre, v. 41, n. 4, p. 1071-1093, out./dez. 2016. 
A pesquisa foi realizada em três escolas dessa rede municipal, selecionadas entre as escolas urbanas, que apresentavam um maior número de evasão do $2^{\circ}$ para o $3^{\circ}$ ano do Ciclo da Adolescência ${ }^{4}$. Participaram do estudo 114 estudantes dessas escolas (61 do sexo f. e 53 do sexo m.) distribuídos em 05 turmas (turma única, escola A; turma única escola B; 03 turmas, escola $C$ ).

O estudo foi realizado em duas etapas. Na primeira, foram coletados dados referentes ao conjunto dos estudantes por meio da adaptação do "balanço de saber" (Charlot, 2009). Em sua versão original, esse instrumento consiste na demanda da produção de um texto individual norteado pelas seguintes questões:

\begin{abstract}
Desde que nasci aprendi muitas coisas, em minha casa, no bairro, na escola e noutros sítios... O quê? Com quem? Em tudo isto, o que é que é mais importante para mim? 'E agora, de que é que estou à espera?' (Charlot, 2009, p. 18).
\end{abstract}

Os/as estudantes que participaram desta etapa $(114)^{5}$ foram convidados a elaborarem seus balanços de saber a partir do seguinte enunciado: você foi convidado a dar uma entrevista para o jornal da cidade. Nesta entrevista a jornalista quer saber sobre a sua experiência na Escola em Tempo Integral: o que você aprende nesta escola? Com quem aprende? Como você fica mais tempo na escola, o que ainda gostaria de aprender? No fim da entrevista, como a jornalista é muito curiosa, ela quer saber também o que poderia aprender, se você ficasse na escola apenas de 7 hàs 11 h30min, sem aulas à tarde. Nesse caso, iria aprender o quê? Onde? Com quem? E aí, vai responder o quê para ela? Capriche, é um grande jornal, com centenas de milhares de leitores.

$\mathrm{Na}$ análise desses textos buscou-se as regularidades que permitissem identificar processos (Charlot, 2009), para “[...] em seguida, construir constelações (configurações, tipos ideais), e não categorizar indivíduos" (Charlot, 2001, p. 22) o "ideal tipo" (Charlot, 2009) do estudante na ETI, e não as diferenças entre alunos singulares.

Na segunda etapa foram coletados dados relativos a trajetórias individuais, ou seja, a processos de construção da relação com o saber vivenciados, de maneira singular, por alguns estudantes. Acompanhando Charlot (2009), não buscamos, ao contrário do que ocorre na etapa anterior, regularidades de um grupo; mas sim, vivências específicas sobre a ETI. As entrevistas foram realizadas com 22 estudantes (11 estudantes do sexo feminino, e 11 estudantes do sexo masculino) escolhidos de modo aleatório ${ }^{6}$ nas 05 turmas. O fio condutor das entrevistas foram as experiências vivenciadas pelos sujeitos na ETI.

Nas relações que os sujeitos deste estudo estabelecem com o saber e com a ETI, eles atribuem diferentes significados às experiências nesta escola, e evidenciam as mobilizações que fazem em direção ao aprender nas atividades propiciadas pelo alargamento do tempo, o que será objeto de análise neste texto.

Educação \& Realidade, Porto Alegre, v. 41, n. 4, p. 1071-1093, out./dez. 2016.1073 
Relação com o Saber na Escola em Tempo Integral

\section{Tempo Integral: múltiplas versões e tensões}

No cenário atual brasileiro, diversas expressões têm comparecido no repertório linguístico nos debates sobre Educação Integral: o próprio termo Educação Integral, que assume diferentes contornos históricos e nuances teórica (Coelho, 2009a; 2009b); jornada ampliada, conforme propõe a Lei de Diretrizes e Bases da Educação Nacional, que prevê a ampliação progressiva do tempo de permanência diário na escola (Brasil, 1996) ${ }^{7}$; Escola em Tempo Integral, em um turno único; Escola Integrada, que oferece atividades socioeducativas no contraturno escolar para todos os alunos ou parte deles; tempo integral, que significa mais tempo diário na escola, e se confunde, por vezes, com escola em tempo integral ${ }^{8}$. Embora guardem diferenças, o mais tempo de jornada escolar diária deve significar um outro tipo de escola, e não somente a ampliação de um tempo do mesmo (Cavaliere, 2007).

Nesse cenário, os argumentos mobilizados organizam-se entre dois polos: o da educação integral e o do mais tempo para as aprendizagens (Coelho; Cavaliere, 2002; Cavaliere, 2007; Cavaliere, 2009; Coelho, 2009a; Fundação Itaú Social, 2011; Moll, 2012a; Coelho, 2012; Cavaliere; Maurício, 2012). Em cada um desses polos, porém, encontram-se várias versões, tensões e até contradições.

No primeiro polo, a própria expressão Educação integral atrai simpatias ao recusar o modelo do aluno preso em uma cadeira, copiando, decorando, fadado às delícias, às vezes duvidosas, do desenvolvimento da sua Razão. Contudo, existe uma versão de educação integral em que integral passa a significar total, com o risco permanente de desvio para totalitária. Educação integral pode ser o que acontecia nos colégios dos Jesuítas no século XVII, ou nos colégios tradicionais da aristocracia inglesa: uma educação em que os adultos pretendiam ao domínio total do psiquismo do jovem e à transparência absoluta, negando, assim, essa parte de privança, até de segredo, a que cada sujeito tem direito.

Por sua vez, mesmo que se considere as diferenças de significados, concepções, tendências, decisões políticas, diferenças sociais e culturais, a expressão Educação Integral, como tem sido discutida hoje no Brasil e em diferentes países, de modo geral, se relaciona a um tempo a mais na escola “[...] associada à multidimensionalidade da formação do sujeito, buscando-se o desenvolvimento integrado de todas as suas potencialidades. Remete, também, à ideia de cidadania e de garantia de direitos" (Leite; Carvalho; Said, 2010, p. 170).

Como transparece nessa citação, o princípio de multidimensionalidade da formação pode ser interpretado em três versões, pelo menos. Uma primeira versão foca uma ideia ampla da cultura, incluindo, em especial, o que a escola atual negligencia: o corpo, o imaginário, a arte. Uma segunda versão destaca a socialização, com a qual a escola contemporânea pouco se preocupa, embora seja ela o lugar em que os

1074 Educação \& Realidade, Porto Alegre, v. 41, n. 4, p. 1071-1093, out./dez. 2016. 
jovens se encontram por várias horas a cada dia - e quando se implanta uma Escola em Tempo Integral, como na experiência analisada -, os jovens passam na escola, juntos, oito horas, ou seja, um terço do dia, isto é a metade do tempo em que não dormem. Uma terceira versão remete à ideia de proteção dos alunos vulneráveis, ou seja, saindo do vocabulário politicamente correto, à socialização dos pobres, ameaçados pelos perigos da rua e, particularmente, pelo consumo e tráfico de drogas.

Cabe observar que essa preocupação com alunos/as vulneráveis aparece, direta ou indiretamente, nos textos que embasam a política de tempo integral. O texto do PNE fixa como meta o atendimento a, no mínimo, $50 \%$ das escolas públicas do país e o atendimento a pelo menos 25\% dos/as alunos/as da educação básica (Brasil, 2014a). Considerando a realidade educacional brasileira com suas dificuldades históricas, tais números indicam que a ampliação da jornada escolar irá priorizar jovens em situação de vulnerabilidade escolar e social, a exemplo do PME destinado, prioritariamente, a estudantes que apresentam defasagem idade/ano; de anos/séries, onde são detectados índices de evasão e/ou repetência e beneficiários do Programa Bolsa Família (Brasil, 2014c).

O outro polo, o do mais tempo para as aprendizagens, tampouco escapa às tensões e contradições. Por um lado, o tempo integral disponibiliza mais tempo para aprender mais coisas, de forma mais aprofundada, e contribui para a democratização da escola; com efeito, alunos/ as socialmente mais afastados da cultura escolar necessitam de mais tempo para aprender. Por fim, os docentes precisam de mais tempo para sair de uma pedagogia memorizar-decorar-esquecer ou de uma pedagogia da fotocópia. Requerem mais tempo as disciplinas que exigem mais explicações (em especial as matérias científicas), as que demandam o exercício de habilidades (Português, Línguas, Matemática, Educação Física), as que precisam de mais tempo de leitura (Português, História) ou de criação (Artes). Desse ponto de vista, o aumento do tempo escolar é uma oportunidade histórica para implantar uma pedagogia mais eficaz, mais inteligente, mais criativa.

Por outro lado, porém, a questão do tempo escolar não se reduz à da duração da jornada escolar. Em primeiro lugar, os estudos de cronobiologia escolar (Testu, 2008) levantam mais questões. Qual deve ser o ritmo anual da escola? Por exemplo, a França adotou um ciclo de seis semanas de aulas e duas semanas de descanso (fora das férias anuais, mais longas), assim como há diferenças da distribuição da jornada escolar em diferentes países (Sacristán, 2008; Maurício, 2014b).

Qual deve ser a distribuição do tempo na semana? A cronobiologia mostra que uma semana escolar com um corte no meio da semana e aulas no sábado é melhor para a saúde e a mobilização intelectual da criança do que a semana de cinco dias consecutivos - mas os pais querem os filhos em casa no sábado. Qual deve ser o equilíbrio das atividades na jornada ampliada? De acordo com esses estudos a melhor opção

Educação \& Realidade, Porto Alegre, v. 41, n. 4, p. 1071-1093, out./dez. 2016.1075 
Relação com o Saber na Escola em Tempo Integral

não é a de programar disciplinas intelectuais pela manhã e arte e esporte pela tarde; observam-se momentos de cansaço no meio da manhã e momento de disponibilidade na tarde (Testu, 2008).

Deve-se levar em conta a idade dos/as alunos/as: não se pode pensar o tempo integral de mesmo modo quando se trata de crianças de 04 anos e de adolescentes de 15 anos. Não se deve esquecer, ademais, o problema das escolas em que faltam professores, quer seja porque não foram nomeados em certas disciplinas, quer seja por causa do absenteísmo, consequência de mal-estar profissional, de salários baixos, em algumas escolas de condições difíceis de trabalho e, por vezes, dos problemas de empenho pessoal no exercício da profissão. Seria um tanto absurdo aumentar a duração da jornada escolar sem enfrentar, de forma séria, o problema das turmas sem professor.

Além das questões que acabamos de levantar, cabe prestar uma grande atenção a um ponto fundamental: não existe uma correlação sistemática entre aprendizagem efetiva e tempo passado na escola. Assim, países como a Finlândia, que aparecem entre os primeiros nas avaliações internacionais das aprendizagens, não têm uma jornada escolar mais longa do que outros com piores resultados. A aprendizagem não está correlacionada com o tempo escolar administrativo, mas com o tempo em que a criança ou o adolescente estuda mesmo, seja na escola, ou fora dela. Importa é o tempo de mobilização intelectual do estudante, independente do lugar. Ou seja, "[...] é a qualidade, não a quantidade, do tempo de aprendizagem que realmente importa" (OCDE, 2011, p. 1).

Cabe refletir que a escola em tempo integral, seja qual for a versão implantada, só pode produzir efeitos (positivos ou negativos) através da relação que os/a alunos/as estabelecem com essa inovação que altera, profundamente, seu ritmo cotidiano, suas rotinas de vida, suas atividades.

\begin{abstract}
Que sentido é que tem para uma criança, nomeadamente para uma criança oriunda de meio popular, ir à escola? Que sentido é que tem para ela aplicar-se na escola ou não? Que sentido é que tem para ela aprender, na escola ou noutro sítio, e compreender? (Charlot, 2009, p. 14).
\end{abstract}

Decidimos prolongar o questionamento acima com referência às pesquisas sobre a relação com o saber e com a escola: que sentido tem para um/a adolescente brasileiro/a ir a uma escola em tempo integral? Para tanto, adotamos neste estudo a teoria da relação com o saber.

Charlot (2000) argumenta que a relação com o saber é um conjunto de relações que o sujeito, confrontado com a necessidade de aprender, estabelece "[...] com o mundo, com o outro, e com ele mesmo" (Charlot, 2000, p. 80). É, pois, o

[...] conjunto das relações que um sujeito mantém com um objeto, um 'conteúdo de pensamento', uma atividade, uma relação interpessoal, um lugar, uma pessoa, uma si-

1076 Educação \& Realidade, Porto Alegre, v. 41, n. 4, p. 1071-1093, out./dez. 2016. 
tuação, uma ocasião, uma obrigação, etc., ligados de uma certa maneira com o aprender e o saber (Charlot, 2000, p. 81, aspas do autor).

Para o autor, o que importa não é a definição “[...] 'em forma' que se adota” (Charlot, 2000, p. 81, aspas do autor), mas a rede conceitual que se estabelece. Para entender a relação com o saber de um sujeito, faz-se necessário entender a sua posição social, mas também a sua história singular, seus desejos, o que o mobiliza para aprender e quais suas atividades no mundo e sobre o mundo.

Nesse sentido, a educação é, pois, um “[...] triplo movimento de humanização, de subjetivação e de socialização (indissociáveis). Ela supõe um processo de apropriação do mundo" que o autor chama de "Aprender ou processo aprender"9 (Charlot, 2001, p. 25). O processo aprender supõe a atividade do sujeito, a mediação do outro, o acesso a universos simbólicos, e é nesse movimento "[...] em que se constrói, [que] o sujeito constrói um mundo - partilhado com outros sujeitos humanos" (Charlot, 2001, p. 25).

É no processo de humanização, socialização e singularização, pelo qual o ser humano, que nasce inacabado, se apropria de uma parte do patrimônio humano e social construído pelas gerações anteriores e o investe numa história singular (Charlot, 2000; 2001; 2005; 2013). Esse patrimônio inclui saberes que a escola ensina outros que ela não incorporou, e, também, "figuras do aprender" (Charlot, 2000, p. 65) - gestos, práticas, formas de intersubjetividade e da subjetividade - que o ser humano descobre e dos quais ele se apropria fora da escola, em um processo que nunca termina, porque o ser humano nunca se acaba (Charlot, 2000; 2001; 2008).

O que está acontecendo com essas aprendizagens fora da escola quando se implanta o tempo integral?

Por sua vez, aprendem-se na escola saberes e competências que não se encontram fora dela. Deve-se acabar com certa arrogância da escola, já que se aprendem muitas coisas importantes em outros lugares; mas esse não deve ser um argumento para desprezar a escola, uma vez que ela dá acesso a aprendizagens específicas, de alta importância humana (Charlot, 2008).

Por serem diferentes dos que se encontram na família e na comunidade - o que, ao mesmo tempo, fundamenta a insubstituibilidade da escola e lhe traz problemas - esses saberes requerem processos específicos e demorados de mobilização do aluno, como Charlot sustenta nas suas pesquisas $(2000 ; 2001 ; 2005 ; 2009 ; 2013)$.

Para o autor, só aprende quem se mobiliza intelectualmente (quem estuda), e só se mobiliza quem encontra na situação proposta um sentido e uma forma de prazer. Encontrar sentido e mobilizar-se no estudo da Matemática, da Química, da História etc. e até na reflexão sobre o Português (que o aluno já fala) requer tempo. Há uma história

Educação \& Realidade, Porto Alegre, v. 41, n. 4, p. 1071-1093, out./dez. 2016.1077 
Relação com o Saber na Escola em Tempo Integral

do desejo de saber, e de saber tal ou qual coisa, uma história que se desenrola no tempo (Charlot, 2000; 2005; 2009; 2013).

São essas reflexões teóricas que nos levam a questionar: uma escola em tempo integral para uma educação integral, ou mais tempo para as aprendizagens? Além de encontrar várias versões, às vezes contraditórias, de cada termo da alternativa, o aprofundamento problemático evidencia uma dupla legitimidade. Por um lado, aprende-se fora da escola; aprender é uma atividade de maior abrangência do que apropriar-se de saberes e competências escolares. Por outro lado, na escola, "[...] ensinam-se coisas que não podem ser ensinadas em outros lugares, sejam essas coisas conteúdos, modos de raciocínio, sejam essas formas de se relacionar com os outros ou consigo mesmo" (Charlot, 2008, p. 179).

Charlot insiste, em seus livros, na heterogeneidade das formas do aprender e convoca o/a pesquisador/a a "[...] explorar e analisar as formas heterogéneas da aprendizagem e da subjetividade" (Charlot, 2009, p. 73). Neste estudo, demos atenção a essa heterogeneidade e à diversidade das formas de aprender. Com efeito, fora da escola, o sujeito aprende outras coisas, de outras maneiras. A vida é mais ampla que a escola e, portanto, é interessante entender o que acontece com o aprender (de forma ampla) quando o tempo de vida, fora da escola, diminui e aumenta o tempo do saber (na sua definição escolar).

Essas reflexões e a análise do material empírico fazem emergir duas questões que nos parecem significativas ao se discutir e propor experiências de tempo integral: o binômio proteção/educação, e a relação ampliação do tempo e aprendizagem.

\section{Tempo Integral e Proteção de Crianças e Adolescentes}

Retirar crianças e jovens da rua é uma justificativa que comparece como lugar comum ao se colocar em debate o tempo integral. Tal justificativa remete ao binômio educação/proteção (Coelho, 2009b), tendência presente nos debates sobre educação integral na contemporaneidade, que atribui à escola um papel fundamental de guarda e vigilância. Esse binômio pode ser um dos argumentos para a universalização do atendimento em tempo integral, como na experiência analisada: "[...] a necessidade de constituir uma ampla rede de proteção e educação exigia que a escola de tempo integral fosse para todos" (UFMG, 2012, p. 21).

Pode também, ao contrário, sustentar a ideia de um público prioritário, como se pode conferir em dois estudos que mapearam as experiências de ampliação da jornada escolar brasileiras (Brasil, 2010a; Brasil, 2010b). Nesses estudos, podem se identificar em sua maioria, como público prioritário (e até mesmo exclusivo), estudantes com baixo desempenho escolar e a organização de atividades complementares para esse público: “[...] a maior parte das experiências, de fato, não contempla

1078 Educação \& Realidade, Porto Alegre, v. 41, n. 4, p. 1071-1093, out./dez. 2016. 
todos os alunos das escolas, o que tem implicações na maneira como a ampliação do tempo é entendida pela comunidade escolar" (Cavaliere; Mauricio, 2012, p. 252).

Da mesma forma, o PME destina-se, prioritariamente, a escolas que apresentam baixo Índice de Desenvolvimento da Educação Básica (IDEB) e àquelas localizadas nos territórios de atenção do Plano Brasil Sem Miséria ${ }^{10}$, aliando aprendizagem e vulnerabilidade social como “[...] estratégia coadjuvante no enfrentamento das desigualdades sociais" (Moll, 2012b, p. 134).

Na experiência analisada neste estudo, a opção da oferta do tempo integral para todos é motivada pela necessidade de fortalecimento da identidade local, pela compreensão da educação como um direito de todos/as, mas também, pela vulnerabilidade social de crianças e jovens. Foi a vulnerabilidade que permitiu à Secretaria Municipal de Educação acessar os recursos do PME, integrando-o ao currículo da ETI. O município figurou, em 2009, na mídia nacional como uma das cidades brasileiras com maior índice de vulnerabilidade juvenil, segundo dados de pesquisas sobre o Índice de Vulnerabilidade Juvenil à Violência (IVJ - V), divulgados pelo Fórum Brasileiro de Segurança Pública e pelo Ministério da Justiça (Brasil, 2009).

Em nossa pesquisa, o que dizem os próprios estudantes a esse respeito?

A análise do material empírico evidencia o argumento da proteção, mas ao mesmo tempo o tensiona, como discutiremos nesta seção.

Nos balanços de saber a proteção é um dos temas recorrentes evocado para denunciar as condições físicas das escolas, especialmente a ausência de espaço, reivindicar mudanças no tempo integral, questionar a dificuldade de conciliar escola, trabalho e outros interesses pessoais, argumentar sobre o cansaço, questionar o tempo integral implantado do mesmo modo para crianças e adolescentes, como podemos ler nos excertos a seguir:

E o combinado que eles fizeram é que $7 \mathrm{~h}$ às $11 \mathrm{~h} 30 \mathrm{~min}$ seriam aulas normais e de $12 \mathrm{~h} 20 \mathrm{~min}$ até $14 \mathrm{~h} 40 \mathrm{~min}$ seria lazer. Disseram que isso era pra tirar os jovens e adolescentes das ruas, mas isso não resolveu o problema, ajudou foi agravar o problema, porque os meninos (jovens e adolescentes) saíram das escolas e foram virar 'vagabundos'. Eles não cumpriram com o combinado que fizeram, muitos tão tendo que passar a estudar à noite. Eu acho que eles tinham que liberar ou criar uma licença para quem está trabalhando ou fazendo cursos ${ }^{11}\left(\mathrm{E}^{12}\right.$, sexo m., 15 anos, aspas do original).

Em minha opinião, a ETI é bom porque as crianças ficam de $7 \mathrm{~h}$ às $15 \mathrm{~h}$, mas só acho que deveria mudar muitas coisas. Acho que isso é só pra segurar nós na escola. Tipo eu, depois do almoço eu durmo porque cansa muito, e ainda tem matemática, inglês, só matéria que exige muito, entende? (E, sexo f., 14 anos).

Educação \& Realidade, Porto Alegre, v. 41, n. 4, p. 1071-1093, out./dez. 2016. 
Relação com o Saber na Escola em Tempo Integral

Para muitas mães é bom porque fica trabalhando até tarde e tem onde deixar seus filhos, mas para nós é difícil porque passar oito horas na escola é muito cansativo. Acordar 6h da manhã e sair 15h não é fácil, não. Queria ver se vocês fossem mais novos iam aguentar tanta tortura... (E, sexo f., 14 anos).

O argumento da proteção aparece também nas entrevistas:

É uma experiência boa porque dá pra gente estudar mais, sair das drogas, [não] ficar lá fora lá correndo risco. A gente fica mais tempo aqui. Eu gosto de estudar em tempo integral (Alan ${ }^{13}, 14$ anos).

O tempo integral não é muito bom, é bom porque tira mais gente da rua (Paulo, 15 anos).

Muitas vezes, o binômio proteção/educação visa justificar a importância do tempo integral como ressaltado nos balanços de saber: para o jovem não mexer com droga; retirar o jovem da rua; retirar o jovem da droga; não fazer o que não deve, é melhor ficar na escola aprendendo; não se envolver com o que não presta.

Entretanto, esse discurso, denominado por uma das entrevistadas como político, é tensionado por alguns estudantes, que ressaltam a fragilidade do binômio educação/proteção:

O tempo integral tem o seu lado bom como tirar jovens imprudentes das ruas (isto é, os que estão matriculados) (E, sexo m., 14 anos).

Se quiser mexer com coisa errada o jovem vai fazer, qualquer hora vai fazer, depois da aula vai fazer (João, 14 anos).

Eles deram palestra sobre o horário integral e falaram que é pra tirar o jovem da rua, tirar a gente do tráfico. Pra isso, a escola em tempo integral não tá valendo de nada. Quem quiser mexer com droga, vai mexer até dentro da escola (Nélio, 14 anos).

Se era pra tirar a gente de um envolvimento que não é bom, o tempo integral não resolve. Muitas pessoas saem da escola e estão na rua (Tiago, 15 anos).

A análise dos dados evidencia que o argumento que alia proteção/educação nas justificativas sobre a ampliação da jornada escolar é questionado pelos próprios jovens entrevistados, como destacado acima. Levando-se em conta os dados relativos à evasão na rede municipal, um número significativo de jovens não se encontram na escola, "estão andando por aí" (E., sexo m., 15 anos), a colega "saiu e foi pra esse mundo aí", [o das drogas] (Olga, 14 anos).

Os dados estatísticos confirmam que o argumento é frágil. O documento Mapa da violência 2014, Os jovens do Brasil (Waiselfisz, 2014), que analisa os Índices de Vulnerabilidade Juvenil à Violência no período de 2008 a 2012, apresenta uma taxa de crescimento da violência juvenil em Governador Valadares que ocupa, no ano de 2012, as primeiras posições entre os municípios do Estado de Minas Gerais com mais de cem mil habitantes. Embora a ETI tenha sido implantada em 2010, a

1080 Educação \& Realidade, Porto Alegre, v. 41, n. 4, p. 1071-1093, out./dez. 2016. 
violência juvenil não decresceu. Portanto, o binômio proteção/educação não é suficientemente eficaz, até mesmo porque os jovens de 14/15 anos, faixa etária mais vulnerável (Waiselfisz, 2014), são os primeiros a deixarem a ETI.

Os/as próprios/as estudantes percebem as tensões e contradições que envolvem a ETI, entendida como visando à proteção dos jovens, e ampliam o espaço do debate: eles e elas participam em projetos que incluem a prevenção à violência, mas não se reduzem a esse objetivo.

Dos 22 (vinte e dois) sujeitos entrevistados, todos participaram ou participam de atividades extraescolares como o Programa Escola Aber$\mathrm{ta}^{14}$, o Programa Fica Vivo ${ }^{15}$, projetos desenvolvidos por uma ONG local e atividades educativas e culturais desenvolvidas por um Instituto e igrejas. De acordo com os relatos nas entrevistas, a participação nesses projetos revestia-se de diferentes significados: como espaço de convivência, lugar de encontro entre jovens; como espaço de aprendizagens - aprendizagem de uma atividade que poderia gerar renda (cursos de manicure e ou cabeleireiro); aprendizagens musicais (muitos aprenderam a tocar instrumentos); aprendizagens de outros idiomas, como o espanhol, por exemplo; aprendizagens de atividades manuais, como modelagem; aprendizagens estéticas como pintura; como espaço de desenvolvimento pessoal - participação em grupos de teatro que os ajudaram a ficar mais desinibidos; participação em atividades desportivas; aprendizagens relacionadas à participação cidadã - os encontros nos projetos são precedidos de debates com vistas à prevenção e discussões sobre o bairro e a cidade.

Por exemplo, em um dos projetos do qual participa uma estudante e um estudante, o propósito era a Mediação de Conflitos no espaço de vivência (a casa, a rua, a escola, o bairro). Neste projeto, os participantes são multiplicadores e o mesmo desencadeia ações comunitárias, como relata Saulo (15 anos):

Saulo: Tô te falando agora meio não como aluno, mas como mediador, que eu já participei do Projeto ‘Mediador de Conflitos’ pra tá auxiliando a escola, passando o que eu aprendi aos alunos, porque a gente pensa: se a família não vai bem o aluno não vai bem. Então o bairro é bastante atendido, tem bastante projetos sociais, tem mediações. Tipo assim, tem os vizinhos que não se entendem... aí vai lá conversar pra fazer a conciliação entre aqueles dois vizinhos, e se for um caso que ocorra a justiça aí encaminha pra justiça, essas coisas assim ... Isso é uma coisa que auxilia na escola, porque aí a família tá bem, o aluno tá bem.

Pesquisadora: Como que é você participou desse projeto?

Saulo: Foram selecionados 04 alunos daqui da escola que considera que tenha mais facilidade de tá falando, que conversa muito, igual eu. Aí selecionaram esses alunos e foram pra lá. Aí envolve pessoa do posto de saúde, pessoas que estão envolvidas com a comunidade, da associação comunitária, e a gente reuniu pra tá vendo isso, tá vendo um conflito ajudar e auxiliar para tá melhorando o bairro.

Pesquisadora: Então você gostou do projeto? 
Relação com o Saber na Escola em Tempo Integral

Saulo: É um projeto muito bacana, a gente não acabou, não parou por aí, a gente tá até hoje, a gente se reúne. Inclusive ontem teve uma reunião. A gente vê muita pichação de muro com frases com apologia ao crime e o nosso projeto é pintar esses muros com frases de paz, que aí a pessoa vai vendo aquilo, uma hora aquilo entra na cabeça.

Nas conclusões do livro Os jovens e o saber, Charlot afirma que “[...] 'aprender a vida' é ingressar na vida humana, mas, para os jovens das camadas populares, é também aprender a se defender e a lutar para $s o$ breviver" (Charlot, 2001, p. 149, aspas e grifos do autor). As escolas da rede municipal de educação encontram-se localizadas em bairros nos quais os/as adolescentes estão muito expostos ao território do tráfico, como os índices de vulnerabilidade juvenil indicam. Não se trata apenas, porém, de protegê-los e sim, de forma mais ampla, de abrir oportunidades para que eles aprendam o que é necessário para sobreviver em seu bairro, para "aprender a vida”, para tornar esta vida melhor. Eles enxergam nos projetos possibilidades para a vida presente e para a vida futura - tanto individual, como coletiva. O bairro em que se vive pode ser melhor, acreditam; e os projetos, as igrejas, a quadra comunitária na qual "jogavam bola” são espaços de socialização.

Entretanto, com a ETI, a inserção dos/das jovens nesses projetos foi reduzida, e por vezes, limitada. Dos estudantes entrevistados, dois retornam à escola para participar do Escola Aberta (permanecendo na escola por 10 horas), outros se dizem cansados e, aos sábados e finais de semana quando estão livres, necessitam cuidar da casa - limpeza e arrumação, realizar pequenos trabalhos, ou ajudar o pai na construção da casa: "meu pai não gostou muito do tempo integral porque não posso ajudar a fazer nossa casa. Agora só posso trabalhar no sábado” (Rui, 14 anos).

Os/as estudantes entrevistados/as que ainda participam de projetos (quatro estudantes) o fazem após as 15h. Em um dos bairros da cidade no qual se localiza um Instituto - lugar de referência para os/as jovens - o horário das atividades mudou para após as 15h, com término antes do anoitecer, pois é perigoso circular à noite no bairro. Com a redução do tempo, há também a redução da participação, como nos relata João (14 anos):

Pesquisadora: Você me falou que às vezes você quer fazer uma oficina e não pode mais por causa do tempo integral. Te atrapalha, como assim? João: Atrapalha tipo assim. O Instituto antigamente era de meio dia até quatro horas tinha oficina, até cinco horas também. Nós gostava [sic] muito do horário normal por causa disso. O Instituto, o tempo era mais prolongado. Agora não. Agora por causa da escola o Instituto é de 3 às 5 [15 às 17h] e não tem muito tempo pra gente se divertir. Entende, por isso nós gostava do horário normal antes [tempo parcial]. Pesquisadora: E vocês iam pro Instituto?

João: Nossa. Era a escola toda. Quase todo mundo ia pro Instituto. Por isso o Instituto é de $3 \mathrm{~h}$ as $5 \mathrm{~h}$, pra ele ficar de pé. Se não num ia ter ninguém. Pesquisadora: O que vocês aprendiam no Instituto?

1082 Educação \& Realidade, Porto Alegre, v. 41, n. 4, p. 1071-1093, out./dez. 2016. 
João: Aula de culinária, de fazer comida, de manicure, teve uma época que lançaram o curso de cabeleireiro, tem aulas de futebol, de handebol, aula de dança. É isso que nós gosta no Instituto, só esporte e lazer. Nós gostava de ficar mais tempo se divertindo do que estudar.

Assim, o tempo integral cerceia a participação juvenil em outros espaços de socialização e aprendizagem. Por sua vez, ao integrar as atividades do PME ao currículo da ETI, busca-se, com as atividades do Programa, ampliar a participação dos/das estudantes em atividades artísticas e culturais. Todavia, essas atividades não tangenciam uma das questões prementes desses jovens: aprender a vida nos bairros em que vivem. Além disso, em uma semana de 40 horas aulas semanais, apenas 05 aulas são atividades do PME - "são poucas, o horário das aulas é muito mais" (Lucas, 15 anos). Sendo assim, as atividades do PME, embora consideradas por eles/elas mais livres, light, criativas, são vistas por alguns como oportunidades para escapar da sala de aula, conversar com os colegas. Aliás, nem todos participam das atividades, como foi possível constatar durante a inserção no campo de pesquisa.

Nesse sentido, nossa pesquisa evidencia um paradoxo, o que a Sociologia chama de efeitos perversos, ou seja, efeitos contrários aos objetivos pretendidos: um dispositivo de escola em tempo integral que visa à multidimensionalidade da formação do sujeito e à proteção dos jovens mais vulneráveis pode reduzir os espaços de formação e as oportunidades de aprender a vida. Não se trata de uma fatalidade, obviamente, mas esses resultados chamam a atenção para a necessidade de construir espaços de formação articulados e flexíveis sem considerar que a ampliação do tempo escolar vai, por si só, realizar uma educação integral.

A ETI, porém, deve ser analisada também com respeito a seu outro objetivo: disponibilizar mais tempo para as aprendizagens.

\section{Ampliação do Tempo e Aprendizagens}

Na análise dos balanços de saber, buscamos identificar as referências feitas nos textos e que relacionavam à jornada escolar (tempo parcial e tempo integral) e à aprendizagem. Nesses textos, os/as estudantes afirmam, em sua maioria, que aprendem mais no tempo integral: aprendemos mais; desenvolvo mais; se ficasse menos tempo, aprenderia menos; no tempo parcial não iria aprender todas as matérias, preferia que os professores ensinassem mais coisas para aprender mais. Vários deles, porém, insistem na questão do cansaço, das muitas horas na escola: não sobra tempo para estudar em casa; já chega cansado e não dá para estudar; a mente fica cansada para aprender; aprendo poucas coisas, porque fica muito tempo na escola; não precisa ficar este horário para aprender; fico esse tempo na escola porque sou obrigado; aprenderia do mesmo modo em tempo integral ou se ficasse menos tempo; se ficasse menos tempo não deixaria de focar nas matérias importantes; não gosto do tempo integral, porque não gosto de estudar.

Educação \& Realidade, Porto Alegre, v. 41, n. 4, p. 1071-1093, out./dez. 2016.1083 
Relação com o Saber na Escola em Tempo Integral

Os balanços e as entrevistas evidenciam a importância do que Charlot e a teoria da relação com o saber chamam de mobilização do aluno - positiva (para aprender mais) ou negativa (não gosto de estudar). "Por que e para que um aluno estuda?" Para compreendê-lo, é preciso interrogar sobre "a mobilização do aluno no estudo" (Charlot, 2013, p. 144-145).

A mobilização é um fenômeno interno. O sujeito "mobiliza-se a si mesmo de dentro" (Charlot, 2013, p. 160). Mobilizar-se significa movimento, engajamento (Charlot, 2000). O colocar-se em movimento, mobilizar-se, ecoa nos balanços e nas entrevistas em palavras como desejar, querer, buscar, ter vontade. Afinal de contas, não importa, para aprender, se o tempo é integral, ou parcial; o que importa é mobilizar-se:

Não adianta. Pode ficar 24 horas dentro da escola sem querer aprender, aí não vai (Caio, 15 anos).

[No tempo parcial] acho que ia aprender menos, mas também poderia aprender mais, eu acho que depende do aluno querer aprender (E., sexo f., 15 anos).

Não importa se a pessoa estuda de $7 \mathrm{~h}$ às $15 \mathrm{~h} 30 \mathrm{~min}$ ou de $7 \mathrm{~h}$ às $11 \mathrm{~h}$ porque se a pessoa quer mesmo estudar, ela aprende (E., sexo f., 14 anos).

É, pois, a mobilização e o sentido que buscamos apreender nos balanços de saber e nas entrevistas no entrecruzamento do tempo e da aprendizagem. Dessa análise, identificamos três processos: estudantes que não entraram nas lógicas da escola e para os/as quais, portanto, o tempo integral é um fardo; estudantes que encontram dificuldades no percurso escolar e para os/as quais a ampliação do tempo faz diferença - mais tempo para aprender; e estudantes que gostam de estudar, para os/as quais o tempo integral amplia e, também, limita as possibilidades de aprender.

\section{Estudantes que não Entraram nas Lógicas da Escola}

Charlot, em diferentes escritos, chama a atenção para os estudantes que, embora fisicamente presentes na escola, nunca entraram efetivamente nela, porque nunca tiveram acesso a suas lógicas simbólicas. “[...] Os alunos nem se evadem, nem abandonam a escola: eles nunca entraram na escola" (Charlot, 2013, p. 161). Encontramos, nesta pesquisa, estudantes que, embora matriculados, faltam muito às aulas ou, mesmo presentes, não estão intelectualmente naquele espaço. Esses/essas estudantes não estabelecem uma relação positiva com a escola, com o estudar; portanto, consideram um peso, uma obrigação sem precedentes frequentar o tempo integral: "Eu não gosto do tempo integral, porque eu não gosto de estudar de 7 h às 11:30min, imagine se eu vou gostar de estudar mais?" (E., sexo m., 15 anos). O estar na escola é, também, uma obrigação que se impõe pelas condições de vida: "Eu acho muito ruim porque ficar 8 horas na escola não é fácil, porque a pessoa que qui-

1084 Educação \& Realidade, Porto Alegre, v. 41, n. 4, p. 1071-1093, out./dez. 2016. 
ser fazer um curso, ou alguma coisa assim, não pode. Vai tá perdendo a bolsa gratuita" [bolsa família] ${ }^{16}$ (E., sexo m., 16 anos).

Para esse grupo, a ampliação do tempo é um fator negativo e que interfere no seu desejo de aprender. Nélio, um estudante de 14 anos, saiu da ETI e foi estudar em uma escola em tempo parcial, mas teve que retornar à escola para acompanhar a irmã menor. Ele diz não faltar às aulas pelo cuidado com a irmã e, quando pode faltar, não consegue - "o pai vigia”. Ele considera mais difícil aprender em tempo integral, porque:

Quando eu ia pra outra escola eu ia animado, sabia que não ia ficar na escola o dia todo; aí eu participava mais da matéria, tudo direitinho. E aqui eu nem faço muita coisa não, a mão pesa, a gente fica cansado, dá sono, a gente nem presta muita atenção (Nélio, 14 anos).

Para não bagunçar a aula, Nélio opta por dormir a maior parte do tempo. Ele resume: "eu estou estudando aqui pra marcar presença, e vê se passo de ano, né?”.

Rui, outro estudante (14 anos), ficou mais de um mês sem ir às aulas, e define com uma palavra o fato de estudar em tempo integral: triste. Para ele, a ampliação do tempo significa "copiar mais matérias e fazer mais bagunça”.

Karen (14 anos) relata, durante a entrevista, que era uma das alunas que mais faltava; diz não gostar muito de estudar. A estudante saiu da ETI e foi para uma escola em tempo parcial, mas este ano não conseguiu vaga nessa escola e teve que retornar ao tempo integral. Sobre as faltas, diz que "dá desânimo de ficar até $15 \mathrm{~h}$ na escola e perde a vontade de vir à aula”. Desistiu de faltar às aulas após a mãe conversar com ela e afirma que agora prefere não faltar, pois "fica muita matéria para copiar".

\section{Estudantes que Encontram Dificuldades na Escola}

Arroyo (2012) alerta que, nas proposições do tempo integral, é preciso superar visões persistentes na educação que tomam as

[...] infâncias-adolescências populares como atrasados mentais, com problemas de aprendizagem, lentos, desacelerados, consequentemente, classificados no percurso seletivo escolar como reprovados, repetentes, defasados, incapazes de seguir com êxito o percurso normal de aprendizagem, logo fracassados escolares e sociais (Arroyo, 2012, p. 37).

Opondo-se a essas análises negativas que procuram identificar nos alunos o que lhes falta para ter sucesso, Charlot propõe a “[...] análise da relação com o saber" que "[...] implica ao contrário uma leitura 'positiva' dessa realidade: liga-se à experiência dos alunos, à sua inter-

Educação \& Realidade, Porto Alegre, v. 41, n. 4, p. 1071-1093, out./dez. 2016.1085 
Relação com o Saber na Escola em Tempo Integral

pretação do mundo, à sua atividade" (Charlot, 2000, p. 30, aspas do autor). O que dizem sobre a ampliação da jornada escolar os próprios alunos com dificuldades de aprendizagem, identificados como prioritários nos textos oficiais? Interessam-nos, na experiência dos/as estudantes, os elementos que eles identificam como importantes na ampliação do tempo para a aprendizagem.

Nos balanços de saber, os/as estudantes relatam dificuldades com disciplinas específicas, mas não abordam a questão das reprovações e da aprendizagem de modo geral. Por sua vez, essa é uma questão que comparece nas entrevistas, possibilitando-nos identificar um grupo de estudantes que declaram suas dificuldades e para os quais a ampliação do tempo faz diferença. João, um dos estudantes que ficou retido no $9^{\circ}$ ano $^{17}$, explica como o tempo integral pode ajudar a recuperar um tempo perdido na escola.

Passaram empurrado até a $8^{\mathrm{a}}\left[9^{\circ}\right.$ ano] de $7 \mathrm{~h}$ as $15 \mathrm{~h}$ dá pra aprender o que não aprendeu antes. Essa escola todo mundo já sabia, desde a $6^{\mathrm{a}}$ até $7^{\mathrm{a}}$ série $^{18}$, eles passaram a gente, muitos passaram empurrado. Assim uns num sabia nem ler, outros sabe mal escrever, outros tem a letra feia, outros tem inteligência zero, outros faltaram demais. A escola passou por presença.

Alan, 14 anos, permanece na escola, duas vezes por semana, 10 horas, participando, além das 8 horas diárias de aula, do Escola Aberta. Para ele, o tempo integral possibilita que aprenda mais, pois "tem mais horários" [mais aulas de uma mesma matéria]. Fábio, 15 anos, ajuda a compreender melhor a importância da ampliação do tempo das aulas:

Fábio: Eu aprendi mais coisas no tempo integral, o tempo parcial passa muito rápido, a gente não aprende quase nada.

Pesquisadora: É? Por quê?

Fábio: O tempo parcial cada vez que você vai à aula, você assusta e já bate o sinal.

Para Saulo, o que faz diferença é a relação professor/aluno, que é

[...] bem bacana. A maioria tem essa relação de professor e aluno que é a amizade mesmo, que a gente passa muito tempo junto, né? $\mathrm{O}$ bacana da gente passar muito tempo junto é essa amizade, que o professor conhece o aluno e o aluno conhece o professor e sabe até onde ele pode ir, e o professor sabe até onde pode ajudar o aluno.

Alan destaca também a oportunidade de utilizar o laboratório de informática e "[...] algumas coisas que a gente tem curiosidade, a gente anota no caderno pra depois ter tipo um debate. Procurar também no dicionário algumas palavras que a gente não sabe o que significa”. Os/as estudantes apontam ainda a paciência do/da professor/a que tem mais tempo para ensinar, de ir na carteira e tirar dúvidas. Também o fato de ter tempo para fazer as atividades na escola faz diferença, deixando de existir o famoso para casa. Em suma, não há dúvida: para os próprios

1086 Educação \& Realidade, Porto Alegre, v. 41, n. 4, p. 1071-1093, out./dez. 2016. 
estudantes que enfrentam dificuldades na escola, sem, por isso, terem desistido de aprender, a ampliação da jornada escolar é positiva.

\section{Estudantes que Gostam de Estudar}

Nas entrevistas, 10 estudantes (06 moças e 04 rapazes) declararam gostar de estudar, como nos relata Geane, 14 anos: "sempre gostei muito de estudar, de aprender coisas novas”. Para eles e elas, a ampliação do tempo significa possibilidades de aprender mais, pois "tem mais aulas", "fica mais tempo com os professores", "mais tempo para explicar a matéria”, “o professor não corre com a matéria”, "aprende mais, o professor tem mais tempo", "eles ensinam bem mais por causa do tempo e a gente aprende bem mais". Ao fator tempo é agregado, portanto, o fator professor:

Agora eles ajudam mais, não fica igual antes quando não era tempo integral. Tinha professor que nem conversava com a gente, passava a matéria e sentava. Agora, no tempo integral, pode chamar quatro vezes na mesa [o professor] que ele te ajuda. Na outra série, eles não faziam isso, não. Falava: vira aí e faz (Lucas, 15 anos).

Entretanto, o tempo integral impõe limites para estudar: “[...] no tempo parcial, você tem mais tempo. Eles [professores] explicam as coisas, você pode chegar em casa e pode estudar" (Vera, 15 anos). Limites, também, para aprender outras coisas e, por isso, Tiago, 15 anos, gostaria de estudar em tempo parcial. Com efeito, o tempo integral impossibilitou que ele se dedicasse ao desenho - atividade que fazia antes do tempo integral - pois uma boa charge, segundo ele, "demora para ser feita". Além disso, o tempo integral reduziu as leituras que fazia e dificulta estudar mais, "pelo cansaço", e se preparar melhor para concorrer a uma vaga do Ensino Médio em um Instituto Federal de Educação; possibilidade que ele enxerga para romper com a história familiar: “[...] é porque minha família [...] nunca teve um bom emprego, então pros meus filhos não continuarem esse ciclo, eu quero começar a mudar para eles ter uma boa educação e assim formar". Tiago avalia suas condições para aprovação e mostra como o tempo integral limita suas possibilidades de estudo:

Tiago: Eu acho que me falta informação pra poder passar nessa prova, isso que eu tô tentando fazer em casa.

Pesquisadora: Que horas você estuda?

Tiago: Estudo sempre à noite. Eu tenho alguns livros, pesquiso na internet e consigo desenvolver um pouco aquilo que não é passado na escola. Pesquisadora: O quê, por exemplo, que não é passado na escola e tem que estudar sozinho?

Tiago: Algumas coisas no livro didático, que eles dão, não são totalmente feitas, não consegue terminar o livro todo na escola, então, eu busco saber, porque a matéria que cai na prova do IF é matéria do $9^{\circ}$ ano, se eu tenho o livro do $9^{\circ}$ ano, e não consigo terminar, vai me faltar alguma coi-

Educação \& Realidade, Porto Alegre, v. 41, n. 4, p. 1071-1093, out./dez. 2016. 
sa na hora da prova. Então, eu tenho que terminar em casa, e entender o que ficou meio apagado na memória e me deixou em dúvida.

Para os/as estudantes que querem sempre aprender mais, o tempo integral pode ampliar as possibilidades de aprender, mas, também, paradoxalmente, ao limitar o tempo fora da escola, ele pode cercear as suas ações e provocar atritos com os desejos de aprender. Será que a escola em tempo integral não consegue possibilitar a Vera e a Tiago tempo para "estudar", como eles querem? Depende do que se faz no tempo da escola.

\section{Qual Escola em Tempo Integral?}

A expressão um tempo do mesmo é utilizada por diferentes autores ao expressarem suas preocupações com o tempo ampliado, para que ele não se converta em um tempo de uma mesma escola, um mesmo tipo de educação (Cavaliere, 2007; Moll, 2012b).

Na proposição da ETI, há um esforço de rompimento com o tempo do mesmo, na organização do currículo por eixos temáticos ${ }^{19} \mathrm{e}$ na construção de um projeto pedagógico em que todos os tempos da escola sejam educativos (tempo das aulas, das refeições, das oficinas).

Entretanto, a ETI permanece um tempo do mesmo quando os/as estudantes relatam, nos balanços e nas entrevistas, sobre o ato de copiar. A escola ainda é um lugar da transcrição - do quadro para o caderno do/a estudante, das telas do computador para os cadernos, ou das cópias Xerox. O tempo do mesmo se repete na divisão do tempo (módulos de 50 minutos), para aulas e oficinas; tempos de recreios e intervalo para o almoço, também, pequenos. A organização espacial e o tempo da escola continuam a ser panópticos, no sentido foucaultiano (Foucault, 2014).

Os/as estudantes provocam-nos a pensar que, em um tempo alargado, a escola teria mais tempo para produzir efeitos de mobilização: em uma aula bem dada, na qual o/a professor/a ensina, apresenta "coisas novas", que os/as envolve; nas aulas nas quais podem se expressar, discutir, debater, defender ideias e pontos de vista; no reconhecimento que fazem sobre a oportunidade de melhoria do relacionamento entre estudantes e professores; na necessidade de escapar da sala para estarem com os/as colegas - oportunidade que encontram nas oficinas do PME; na reivindicação que fazem sobre os/as espaços inadequados (banheiros sem chuveiros, poucas ou ausência de quadras, refeitórios pequenos, ausência de laboratórios). As oficinas do PME são também objeto de análise. Eles/elas reivindicam no currículo outras oficinas e desejam aprender arte, literatura, teatro, música, culinária, cultivo de hortas e plantas. Na escola em tempo integral, os alunos querem... ter tempo:

1088 Educação \& Realidade, Porto Alegre, v. 41, n. 4, p. 1071-1093, out./dez. 2016. 
Eu comecei a desenhar desde a quarta série, sempre gostei de desenhar mesmo, olha que desenhar cansa mais que copiar. Mas desenhar é mais divertido... Você tá copiando no quadro alguma coisa, você tem que acabar junto com o professor. O desenho não. Você pode desenhar despreocupado, não precisa de terminar rápido, ainda mais que você tem que desenhar lento pra sair certo. O desenho, pra nós, é como se fosse o professor Pedro. Ele sabe entender, e espera a gente copiar o dever. Então, o desenho é igual o Pedro: ele espera ser feito, espera a gente fazer tudo lentamente sem errar. O Pedro, ele gosta que não erra nada no dever. No quadro, ele passa e espera um tempão pra gente copiar. Igual o professor de arte. Ele dá o desenho e deixa um tempão desenhando (João).

Qual escola em tempo integral? Vários, tensos e, às vezes, contraditórios são os modelos disponíveis, como evidencia a nossa pesquisa e como o percebem os próprios estudantes. Com certeza, não pode ser uma simples ampliação da escola atual, percebida por muitos jovens como uma obrigação que os adultos impõem aos jovens, para estes terem uma "vida normal" (Charlot, 2009). Quando a escola é só um lugar para passar de ano, não se pode esperar que os/as alunos/as aprovem o tempo integral; pode ser até a gota d'água que os/as leva a desistir completamente da escola. A escola em tempo integral só será um sucesso se ela conseguir ser um espaço-tempo em que aprender tenha sentido, mobilize os alunos, traga para eles essa forma de prazer que se experimenta ao superar desafios. Com alguns alunos, que não gostam de aprender, o objetivo é construir o próprio sentido da escola. Com outros, que aliam boa vontade escolar e dificuldades para aprender, trata-se de disponibilizar o tempo que permite aprender; não esqueçamos de que escola deriva de uma palavra grega que significa lazer; a escola é um lugar em que se deve ter tempo para aprender e não um lugar em que o professor corre, acompanhado por uns poucos alunos, enquanto os demais tentam aguentar. Com os alunos que gostam de aprender, a ETI pode ir mais longe, mas ela deve possibilitar que eles codefinam seus percursos de aprender. A todos os alunos, seja qual for a sua relação com a escola, a ETI pode oferecer oportunidades culturais novas.

O desafio da escola em tempo integral, entretanto, não é apenas pedagógico, é também social e, logo, político. Nossa pesquisa evidencia que, às vezes, a ETI cerceia ou empobrece projetos, dispositivos, desejos. Não se trata, obviamente, de aceitar dedicar todo o tempo novo ao futebol e à culinária, porque "Matemática é chata e Português, já sei falar" - como iria acontecer se fossem atendidos os desejos dos jovens que "não gostam de aprender". Mas, às vezes, o tempo integral impossibilita ou dificulta muito projetos institucionais ou individuais que têm um real valor de formação. Desse ponto de vista, cabe pensar em redes de formação em tempo integral. Para enfrentar a variabilidade das situações, é preciso aceitar uma flexibilidade dos dispositivos de educação em tempo integral. O risco, porém, é desenvolver dispositivos para os ricos e dispositivos para os pobres, que aumentem as desigualdades atuais. Esta é uma nova tensão: quanto mais flexível o dispositivo, mais 
exigente deve ser sua coordenação. O que requer uma verdadeira vontade política. A escola em tempo integral, ou a rede de formação em tempo integral, é um assunto pedagógico, social e político que requer um engajamento de toda a sociedade, incluídos os próprios jovens. Senão, será mais um fazer de conta, mais uma oportunidade perdida ${ }^{20}$.

Recebido em 04 de novembro de 2015 Aprovado em 30 de junho de 2016

\section{Notas}

1 Atualmente são 63 escolas em tempo integral.

2 O PME foi instituído pela Portaria Interministerial no 17/2007 (Brasil, 2007), visando fomentar propostas de educação integral apoiando o desenvolvimento de atividades socioeducativas no contraturno escolar.

3 Dados de matrículas (2009 a 2015) disponibilizados pela Secretaria Municipal de Educação.

4 A ETI adota uma concepção de ciclos de desenvolvimento humano para organização das turmas: Educação Infantil ( 0 a 6 anos); Ciclo da Infância (6 a 8 anos); Ciclo da Pré-Adolescência (9, 10, 11 anos); Ciclo da Adolescência (12, 13, 14 anos) (Governador Valadares, 2009).

5 Todos os estudantes frequentes às aulas (119) foram convidados a elaborarem seus balanços de saber. 114 se dispuseram a participar. Este estudo respeita as normas éticas da pesquisa envolvendo seres humanos.

6 Todos os estudantes das 05 turmas foram convidados a participar das entrevistas e foi feito um sorteio para a seleção dos sujeitos entrevistados. Em cada turma foram selecionados 04 sujeitos, observando a paridade de sexo. $\mathrm{Na}$ escola C, em uma das turmas, foram sorteados mais dois sujeitos, a pedido dos/as estudantes.

7 Conferir artigo 34, $\S 2^{\circ}$ da lei citada (Brasil, 1996).

8 Sobre essas diferenças, sugerimos conferir Maurício (2014a)

9 Charlot esclarece que a apropriação do mundo se dá pelo aprender. Nesse sentido, a relação com o aprender é mais ampla que a relação com o saber. O autor salienta que continuará a usar a expressão "relação com o saber", que é uma forma específica de relação com o aprender para evitar "uma expressão tão pesada, e de jargão, como 'o aprender'. Além disso, a expressão 'relação com o saber' já entrou no vocabulário das ciências humanas” (Charlot, 2000, p. 74, aspas do autor).

10 Informações disponíveis em: <http://www.brasilsemmiseria.gov.br/>. Acesso em: 26 set. 2015.

11 Os balanços de saber não foram nominais. Foram informados o sexo e a idade. Ao citar os balanços, corrigimos a ortografia, mas respeitamos integralmente a fala dos sujeitos.

12 Estudante.

13 Nomes fictícios para preservar a identidade dos/das entrevistados/as.

14 O Programa apoia a abertura, nos finais de semana, de unidades escolares públicas localizadas em territórios de vulnerabilidade social. A estratégia

1090 Educação \& Realidade, Porto Alegre, v. 41, n. 4, p. 1071-1093, out./dez. 2016. 
potencializa a parceria escola/ comunidade ao ocupar criativamente o espaço escolar com atividades educativas, culturais, esportivas, de formação inicial para o trabalho e geração de renda. Informações disponíveis: <http://www. fnde.gov.br/fnde/legislacao/resolucoes/itemlist/tag/Escola\%20aberta $>$. Acesso em: 03 set. 2015 .

15 O Programa tem por objetivo controlar e prevenir a ocorrência de homicídios dolosos em áreas com altos índices de criminalidade violenta em Minas Gerais. Criado em 2003, faz acompanhamento especializado e oferece cerca de 600 oficinas voltadas para o esporte, a arte e a cultura para jovens de 12 a 24 anos em situação de risco social. Informações disponíveis em: <https://www.seds. mg.gov.br>. Acesso em 03 jun. 2016.

16 Informações disponíveis em: <http://www.mds.gov.br/>. Acesso em: 03 set. 2015.

17 A situação escolar de cada estudante entrevistado/a foi acompanhada por meio das atas dos Conselhos de Classe.

18 Na concepção de ciclo adotada pela rede municipal, a retenção é prevista para o $9^{\circ}$ ano.

19 Eixo Comunicação e Múltiplas Linguagens: Português, Matemática, Língua Estrangeira, Arte; Eixo Identidade e Diversidade: História, Ensino Religioso, Educação Física; Eixo Protagonismo e Sustentabilidade: Geografia e Ciências (Governador Valadares, 2009).

20 A pesquisa contou com o apoio do Conselho Nacional de Desenvolvimento Científico e Tecnológico - CPNq.

\section{Referências}

ARROYO, Miguel Gonzalez. O Direito a Tempos-Espaços de um Justo e Digno Viver. In: MOLL, Jaqueline et al. Caminhos da Educação Integral no Brasil: direito a outros tempos e espaços educativos. Porto Alegre: Penso, 2012. P. 33-45.

BRASIL. Lei no 9.324, de 20 de dezembro de 1996. Estabelece as Diretrizes e Bases da Educação Nacional. Diário Oficial [da República Federativa do Brasil], Brasília, DF, v. 134, n. 248, 23 dez. 1996. Seção 1. P. 27834-27841.

BRASIL. Portaria Interministerial no. 17, de 24 de abril de 2007. Institui o Programa Mais Educação. Diário Oficial [da República Federativa do Brasil], Brasília, DF, n. 17, 24 abr. 2007.

BRASIL. Ministério da Justiça. Secretaria Nacional de Segurança Pública. Fórum Brasileiro de Segurança Pública. Projeto Juventude e Prevenção da Violência. Índice de Vulnerabilidade Juvenil à Violência - IVJ. Fundação SEADE, 2009. Disponível em: <http://www.soudapaz.org/upload/pdf/ndice_de_vulnerabilidade_juvenil_viol_ncia.pdf>. Acesso em: 18 set. 2015.

BRASIL. Ministério da Educação. Educação Integral/Educação Integrada e(m) Tempo Integral: concepções e práticas na educação brasileira. Mapeamento das experiências de jornada escolar ampliada no Brasil: estudo quantitativo. Brasília: MEC, 2010a. Disponível em: <http://portal.mec.gov.br>. Acesso em: 20 set. 2015.

BRASIL. Ministério da Educação. Educação Integral/Educação Integrada e(m) Tempo Integral: concepções e práticas na educação brasileira. Mapeamento das experiências de jornada escolar ampliada no Brasil: estudo qualitativo. Brasília: MEC, 2010b. Disponível em: <http://portal.mec.gov.br>. Acesso em: 20 set. 2015.

Educação \& Realidade, Porto Alegre, v. 41, n. 4, p. 1071-1093, out./dez. 2016.1091 
Relação com o Saber na Escola em Tempo Integral

BRASIL. Lei $n^{\circ} n^{\circ} 13$ 005/2014, de 25 de junho de 2014. Aprova o Plano Nacional de Educação - PNE e dá outras providências. Diário Oficial [da República Federativa do Brasil], Brasília, DF, 26 jun. 2014. P. 1. 2014a.

BRASIL. Ministério da Educação. Secretária de Articulação com os Sistemas de Ensino. Planejando a Próxima Década: conhecendo as 20 metas do Plano Nacional de Educação. Brasília, 2014b. Disponível em: <http://pne.mec.gov.br/>. Acesso em: 20 set. 2015.

BRASIL. Ministério da Educação. Secretaria de Educação Básica. Diretoria de Currículos e Educação Integral. Manual Operacional de Educação Integral. Brasília, 2014c. Disponível em: <http://portal.mec.gov.br/index.php>. Acesso em: 19 set. 2015.

CAVALIERE, Ana Maria Vilella. Tempo de Escola e Qualidade na Educação Pública. Educação \& Sociedade, Campinas, v. 28, n. 100 (Especial), p. 1015-1035, out. 2007.

CAVALIERE, Ana Maria Vilella. Escolas de Tempo Integral Versus Alunos em Tempo Integral. Em aberto, Brasília: Instituto Nacional de Estudos e Pesquisas Educacionais Anísio Teixeira, v. 22, n. 80, p. 51-63, abr. 2009.

CAVALIERE, Ana Maria Vilella; MAURÍCIO, Lúcia Velloso. A Ampliação da Jornada Escolar nas Regiões Nordeste e Sudeste: sobre modelos e realidades. Educação em Questão, Caicó, Universidade Federal do Rio Grande do Norte, v. 42, p. 251-273, 2012.

CHARLOT, Bernard. Da Relação com o Saber: elementos para uma teoria. Porto Alegre: Artes Médicas, 2000.

CHARLOT, Bernard (Org.). Os Jovens e o Saber: perspectivas mundiais. Porto Alegre: Artes Médicas, 2001.

CHARLOT, Bernard. Relação com o Saber, Formação dos Professores e Globalização. Questões para a educação hoje. Porto Alegre: Artmed, 2005.

CHARLOT, Bernard. Fundamentos e usos do conceito de relação com o saber. In: DIEB, Messias (Org.). Relações e Saberes na Escola: os sentidos do aprender e do ensinar. Belo Horizonte: Autêntica Editora, 2008. P. 173-181. (Coleção Leitura, Escrita e Oralidade).

CHARLOT, Bernard. A Relação com o Saber nos Meios Populares. Uma investigação nos liceus profissionais de subúrbio. Porto: Livpsic, 2009.

CHARLOT, Bernard. Da Relação com o Saber às Práticas Educativas. São Paulo: Cortez, 2013.

COELHO, Ligia Martha Coimbra da Costa; CAVALIERE, Ana Maria Vilella (Org.). Educação Brasileira e(m) Tempo Integral. Petrópolis: Vozes, 2002.

COELHO, Lígia Martha Coimbra da Costa (Org.). Educação Integral em Tempo Integral: estudo e experiências em processo. Petrópolis: DP ET Alii, Rio de Janeiro: FAPERJ, 2009a.

COELHO, Lígia Martha Coimbra da Costa. História(s) da Educação Integral. Em Aberto, Brasília: Instituto Nacional de Estudos e Pesquisas Educacionais Anísio Teixeira, v. 22, n. 80, p. 83-96, abr. 2009b.

COELHO, Lígia Martha Coimbra da Costa. Alunos no Ensino Fundamental, Ampliação da Jornada Escolar e Educação Integral. Educar em Revista, Curitiba: Editora UFPR, n. 45, p. 73-89, jul./set. 2012.

FOUCAULT, Michel. Vigiar e Punir: nascimento da prisão. Tradução de Raquel Ramalhete. 42 ed. Petrópolis: Vozes, 2014.

1092 Educação \& Realidade, Porto Alegre, v. 41, n. 4, p. 1071-1093, out./dez. 2016. 
FUNDAÇÃO ITAÚ SOCIAL. Tendências para Educação Integral. São Paulo: CENPEC, 2011. Disponível em: <http://www.cenpec.org.br/biblioteca/educacao/producoes-cenpec $>$. Acesso em: 12 dez. 2014.

GOVERNADOR VALADARES. Secretaria Municipal de Educação. Escola em Tempo Integral. Caderno 1. Governador Valadares, 2009.

INSTITUTO NACIONAL DE ESTUDOS E PESQUISAS EDUCACIONAIS (INEP). Pisa em Foco. v. 3. Disponível em: <http://portal.inep.gov.br/pisa-em-foco >. Acesso em: 01 out. 2015.

LEITE, Lúcia Helena Alvarez; CARVALHO, Levindo Diniz; SAID, Camila do Carmo (Org.). Educação Integral e Integrada: Módulo III - educação integral e integrada: reflexões e apontamentos. Belo Horizonte: UFMG - Faculdade de Educação, 2010.

MAURÍCIO, Lúcia Veloso. Tempos e Espaços Escolares: experiências, políticas e debates no Brasil e no mundo. Rio de Janeiro: Ponteio, 2014a.

MAURÍCIO, Lúcia Veloso. Ampliação da Jornada Escolar: configurações próprias para diferentes contextos - Brasil e Europa. Ensaio: avaliação e políticas públicas em educação, Rio de Janeiro, v. 22, n. 85, p. 875-898, out./dez. 2014b.

MOLL, Jaqueline et al. Caminhos da Educação Integral no Brasil: direito a outros tempos e espaços educativos. Porto Alegre: Penso, 2012a.

MOLL, Jaqueline. A agenda da educação integral: compromissos para sua consolidação como política pública. In: MOLL, Jaqueline et al. Caminhos da Educação Integral no Brasil: direito a outros tempos e espaços educativos. Porto Alegre: Penso, 2012b. P. 129-146.

SACRISTÁN, José Gimeno. El Valor del Tiempo en Educación. Madrid: Morata, 2008. TESTU, François. Rythmes de Vie et Rythmes Scolaires: aspects chronobiologiques et chronopsychologiques. Issy-les-Moulineaux: Elsevier Masson, 2008.

UNIVERSIDADE FEDERAL DE MINAS GERAIS - UFMG. Faculdade de Educação. Grupo Teia - Territórios, Educação Integral e Cidadania. Relatório do Projeto de Avaliação e Monitoramento do Programa Escola de Tempo Integral (ETI) da Secretaria Municipal de Educação de Governador Valadares - MG. Belo Horizonte, 2012. P. 128.

WAISELFISZ, Julio Jacobo. Mapa da Violência 2014: Os jovens do Brasil. Brasília: FLACSO, 2014. Disponível em: <www.juventude.gov.br/juventudeviva >. Acesso em: 29 set. 2015 .

Maria Celeste Reis Fernandes de Souza é docente do Programa de Pós-Graduação Stricto Sensu Gestão Integrada do Território da Universidade Vale do Rio Doce (UNIVALE). Vinculada aos grupos de pesquisa Núcleo Interdisciplinar em Saúde, Educação e Direitos (NIESD/UNIVALE) e Educação e Contemporaneidade (EDUCON/UFS).

E-mail: celeste.br@gmail.com

Bernard Charlot é professor titular emérito em Ciências da Educação na Universidade de Paris 8, e atualmente Professor-Visitante na Universidade Federal de Sergipe.

E-mail: bernard.charlot@terra.com.br 